MATEC Web of Conferences 13,03005 (2014)

DOI: $10.1051 /$ matecconf/ 20141303005

(C) Owned by the authors, published by EDP Sciences, 2014

\title{
Hot Corrosion Studies in Coal Fired Boiler Environment
}

\author{
${ }^{*}$ Subhash Kamal ${ }^{1}$, Chennupati Vijya Kumar², A.M. Abdul-Rani ${ }^{1,3}$ \\ ${ }^{1}$ Department of Petroleum Engineering, Universiti Teknologi PETRONAS, Bander Seri Iskander, \\ Tronoh 31750, Malaysia \\ ${ }^{2}$ SSIT, B. Gagaram (V), Sathupally-Khammam. Andhra Pradesh, INDIA \\ ${ }^{3}$ Centre for Intelligent Signal \& Imaging Research, Universiti Teknologi PETRONAS, 31750 Tronoh, \\ Perak, Malaysia
}

\begin{abstract}
Hot corrosion behaviour of the bare and D-gun coated superfer $800 \mathrm{H}$ exposed to low temperature super-heater zone of the coal fired boiler of Guru Nanak Dev Thermal Power Plant, Bathinda, Punjab, India. The specimens were hanged in the platen superheater of coal fired boiler where the gas temperature was around $900{ }^{\circ} \mathrm{C} \pm 10{ }^{\circ} \mathrm{C}$. Hot corrosion experiments were performed for 10 cycles, each cycle consisting of 100 hours exposure followed by 1 hour cooling at ambient temperature. Weight change measurements were done at the end of each cycle. The weight change data used for predicting hot corrosion behaviour of the coated alloys after the total exposure of 1000 hours. The different phases and their distribution in the hot corroded specimens were analysed with the help of FE-SEM/EDS and X-ray mapping .
\end{abstract}

\section{Introduction}

Hot corrosion is one of the serious problems for high temperature application, such as aircraft, marine, utility, industrial and land-base gas turbines, boilers, oil refinery furnace and engines. The use of wide range of fuels from natural gas, kerosene, diesel oils, residual oils and gaseous fuels coupled with increased operating temperatures cause hot corrosion [1]. Hot corrosion is an accelerated corrosion, resulting from the presence of salt contaminants such as $\mathrm{Na}_{2} \mathrm{SO}_{4}, \mathrm{NaCl}$, and $\mathrm{V}_{2} \mathrm{O}_{5}$ that combine to form molten deposits, which damage the protective surface oxides [2]. Unacceptable corrosion rates have occurred when biofuel fired boiler has been operated with steam temperature of $530^{\circ} \mathrm{C}$ [3]. However, these lower steam temperatures drastically decrease the efficiency of electricity production.

In energy generation processes the mechanism of hot corrosion is dependent on the formation of a liquid phase that is predominantly $\mathrm{Na}_{2} \mathrm{SO}_{4}$ or $\mathrm{K}_{2} \mathrm{SO}_{4}$. The sulphur released from the coal, forms $\mathrm{SO}_{2}$ with a minor amount of $\mathrm{SO}_{3}$ and reacts with the volatilised alkalis to form $\mathrm{Na}_{2} \mathrm{SO}_{4}$ vapour, which then condenses together with fly ash on the superheater and reheater tubes in the boiler. Such a liquid phase dissolves the chromium oxide in the protective coating, which allows the base metal to react with sulphate ions to form sulphide ions and non-protective oxides [4-5] 


\section{Experimental Procedures}

\subsection{Substrate Materials}

The Fe-based superalloy namely Superfer $800 \mathrm{H}$ have been selected as the substrate material for the present study. The alloy were procured from Mishra Dhatu Nigam Limited, Hyderabad (India) in the rolled sheet form, for protecting them against high temperature corrosive environment applications.

\subsection{Feedstock materials for the coatings}

Commercially available alloy powders namely NiCoCrAlYTa (Sulzer metco) were chosen for D-gun spray deposition on the superalloy substrates. The chemical composition and particle size of the alloy powders are reported in Fig.1 and Table 1.

Table. 1 Composition of the alloy powders, shape and size of the particles.

\begin{tabular}{|c|c|c|c|}
\hline Alloy powders & $\begin{array}{c}\text { Chemical Composition (Wt. } \\
\%)\end{array}$ & Shape & Particle Size \\
\hline $\begin{array}{l}\text { NiCoCrAlYTa } \\
\text { Sulzer metco } \\
\text { (Amdry 997) }\end{array}$ & $\begin{array}{c}\mathrm{Ni}-23 \mathrm{Co}-20 \mathrm{Cr}-8.5 \mathrm{Al}-4 \mathrm{Ta}- \\
0.6 \mathrm{Y}\end{array}$ & spheroidal & $5-37 \mu$ \\
\hline
\end{tabular}

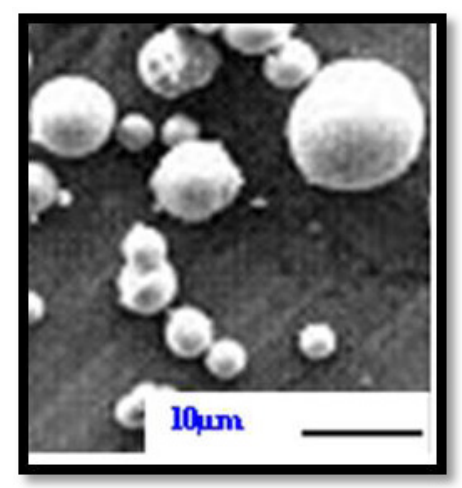

Figure. 1: SEM of NiCoCrAlYTa powder

\subsection{Studies in coal fired Industrial boiler Environment}

The D-gun coated as well as bare superalloy specimens were exposed to the platen superheater zone of the coal fired boiler of Stage-II at Guru Nanak Dev Thermal Plant, Bathinda, Punjab (India). The coated as well as bare specimens were then hanged with the help of a stainless steel wire through the soot blower dummy points at $27 \mathrm{~m}$ height from the base of the boiler. The specimens were exposed to the combustion environment for 10 cycles. Each cycle consisted of 100 hours heating followed by 1 hour cooling at ambient conditions. The temperature was measured at regular intervals during the study and the average temperature was about $900{ }^{\circ} \mathrm{C}$ with variation of $\pm 10^{\circ} \mathrm{C}$. After the end of each cycle the specimens were visually observed for any change in the surface texture, further it has been washed by acetone and weight of the specimens were measured subsequently using an Electronic Balance Model CB-120 (Contech, Mumbai, India, and sensitivity $\left.10^{-3} \mathrm{~g}\right)$. 


\section{Results}

\subsection{Corrosion Kinetics}

The weight change per unit area $\left(\mathrm{mg} / \mathrm{cm}^{2}\right)$ versus time plot for 1000 hours exposure of bare and D-gun coated NiCoCrAlYTa on superfer $800 \mathrm{H}$ to the boiler environment is shown in Fig. 2 The weight

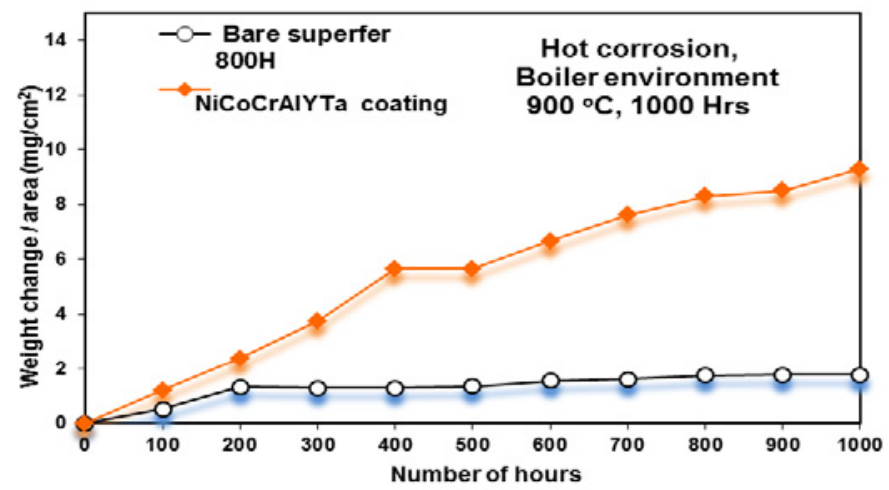

Figure 2 : Weight change vs. time plots for the bare and D-gun coated superfer $800 \mathrm{H}$ subjected to $1000 \mathrm{hrs}$ cyclic exposure to low temperature superheater zone of the coal fired boiler at $900{ }^{\circ} \mathrm{C}$

change in case of coated sample is consisting of the scale formation at the top surface of the coating by reaction and also from the partial oxidation of the coating elements like $\mathrm{Cr}, \mathrm{Al}$ and $\mathrm{Ce}$ at the splat boundaries. The partially oxidised coating remains intact and adherent to substrate, preventing further attack on the substrate superalloy. This partially oxidised coating provides protection against the boiler environment. Bare superfer $800 \mathrm{H}$ shows the lowest weight gain, erosion combined with oxide scale spallation is attributed to lower weight gain. The weight change/area versus time plot for bare and D-gun coated superfer $800 \mathrm{H}$ is shown in Fig.2. It is observed that all the coated and bare coated superfer $800 \mathrm{H}$ follows the parabolic rate law, The parabolic rate constants (kp in $\left.10^{-10} \mathrm{~g} 2 \mathrm{~cm}-4 \mathrm{~s}-1\right)$ for the bare and NiCoCrAlYTa coated superfer $800 \mathrm{H}$ was found to be 0.86 , and 25 respectively.

\subsection{X-ray mapping analysis}

The BSE images of the bare superfer $800 \mathrm{H}$ show uppermost part of the scale consisting mainly iron, nickel, chromium (Fig.3). In the subscale region, the scale has cracked which mainly consist of $\mathrm{Cr}_{2} \mathrm{O}_{3}$ and $\mathrm{SiO}_{2}$ as evident from the $\mathrm{O}$ distribution. During the course of study, oxygen might have penetrated deep in to the substrate along the cracks of weak oxide scale. Oxygen, silicon and chromium are existing mainly in the black region of the scale, where all other elements are depleted. Tinges of Al and Ti have also been observed in the scale. Elemental X-ray mapping analysis of the scale formed on D-gun sprayed NiCoCrAlYTa coated superfer $800 \mathrm{H}$ (Fig.4) indicates that the scale formed on the surface is adherent and continuous. The topmost layer of the scale is found to be enriched with oxides of $\mathrm{Ni}, \mathrm{Fe}, \mathrm{Si}, \mathrm{Al}$ and $\mathrm{Cr}$. In the subscale region, the coating has Ni-rich splats which are in un-oxidised state, whereas $\mathrm{Cr}$ has partially oxidised along the Ni-rich splat boundaries. An aluminum and silicon oxide is found along the coating-substrate interface; also a small amount of Si has diffused in to the top surface of coating during initial cycles of hot corrosion run. Another possibility of aluminum at the coating-substrate interface may be due to entrapped alumina particles, which might be retained in the asperities during grit blasting of the substrate prior to deposition of the coatings. Iron has diffused in to the coating and formed a band just above the coating-substrate interface. Also some traces of iron in the topmost layer of the scale indicate its diffusion behaviour from the substrate to the coating 


\section{Discussion}

The lower weight gain of bare superfer $800 \mathrm{H}$ than its coated counterpart might be attributed to spallation of the oxide scale in the actual environment of the coal fired boiler and fluxing action of the molten salt along with erosion of oxide scale. The most common deposit found on boiler super heaters is sodium vanadyl vanadate, $\mathrm{Na}_{2} \mathrm{O} . \mathrm{V}_{2} \mathrm{O}_{4} .5 \mathrm{~V}_{2} \mathrm{O}_{5}$, which melts at a relatively low temperature, $550{ }^{\circ} \mathrm{C}$, above the melting point, this ash material corrodes metals by long-term contact [6]. The weight gain plots (Fig.2) clearly indicate that the NiCoCrAlYTa coated superalloy superfer $800 \mathrm{H}$ follow a parabolic rate law up to 10 cycles of 1000 hours. The values of parabolic rate constant $\mathrm{kp}\left(2510^{-10} \mathrm{~g}^{2}\right.$ $\mathrm{cm}^{-4} \mathrm{~s}^{-1}$ ) were obtained from slope of the linear regression fitted line. The BSE images of the bare superfer $800 \mathrm{H}$ shows uppermost part of the scale consisting mainly iron, nickel, chromium. In the subscale region, the scale has cracked which mainly consist of $\mathrm{Cr}_{2} \mathrm{O}_{3}$ and $\mathrm{SiO}_{2}$ as evident from the $\mathrm{O}$ distribution. During

the course of study, oxygen might have penetrated deep in to the substrate along the cracks of weak oxide scale. Oxygen, silicon and chromium are existing mainly in the black region of the scale, where all other elements are depleted. Tinges of $\mathrm{Al}$ and Ti have also been observed in the scale. The BSE images (Fig.4) of the coated superfer $800 \mathrm{H}$ show that the coating partially got oxidised with intimate contact with the substrate and indicate the absence of oxygen at the substrate. The presence of oxygen in the coating indicates the penetration of oxygen during the initial exposure to the boiler environment. Oxide stringers of chromium and aluminum have formed along the splat boundaries. Oxides of $\mathrm{Al}$ and $\mathrm{Cr}$ along nickel- and $\mathrm{Co}$ - rich splat boundaries have plugged/sealed the pores and inter splat boundaries and acted as diffusion barriers to the inward diffusion of corrosive species through the NiCoCrAlYTa coatings. The presence of these phases in the scale of coated superalloy is supported by X-ray mapping analyses (Fig.4). Oxygen elemental maps for the coated superalloy confirm that the diffusion of oxygen is restricted to scale-substrate interface and substrate alloy indicates no sign of oxidation Therefore, it is concluded that the NiCoCrAlYTa coating has provided necessary protection to superfer $800 \mathrm{H}$ alloy in the coal fired boiler environment.

\section{Conclusions}

1. Bare superfer $800 \mathrm{H}$ shows spallation and erosion under cyclic test condition after 1000 hours exposure at $900 \mathrm{oC}$ in coal fired boiler environment leads to internal corrosion attack up to few microns

2. All the coatings on the superfer $800 \mathrm{H}$ used in the present investigation have provided resistance to corrosion in coal fired boiler environment at platen superheater zone when exposed for 1000 hours for 10 cycles at $900 \mathrm{oC}$ and have shown the following trend of resistance to corrosion

3. D-gun spraying process has been successfully used to deposit NiCoCrAlYTa coatings on Febased superalloys. The coatings have protected the substrate in boiler environment. The coating can be used on all those surfaces which are facing the fire side corrosion such as in internal combustion engines, industrial waste incinerators, fluidized beds, gas turbine or steam turbines, to provide protection against degradation in these environments 


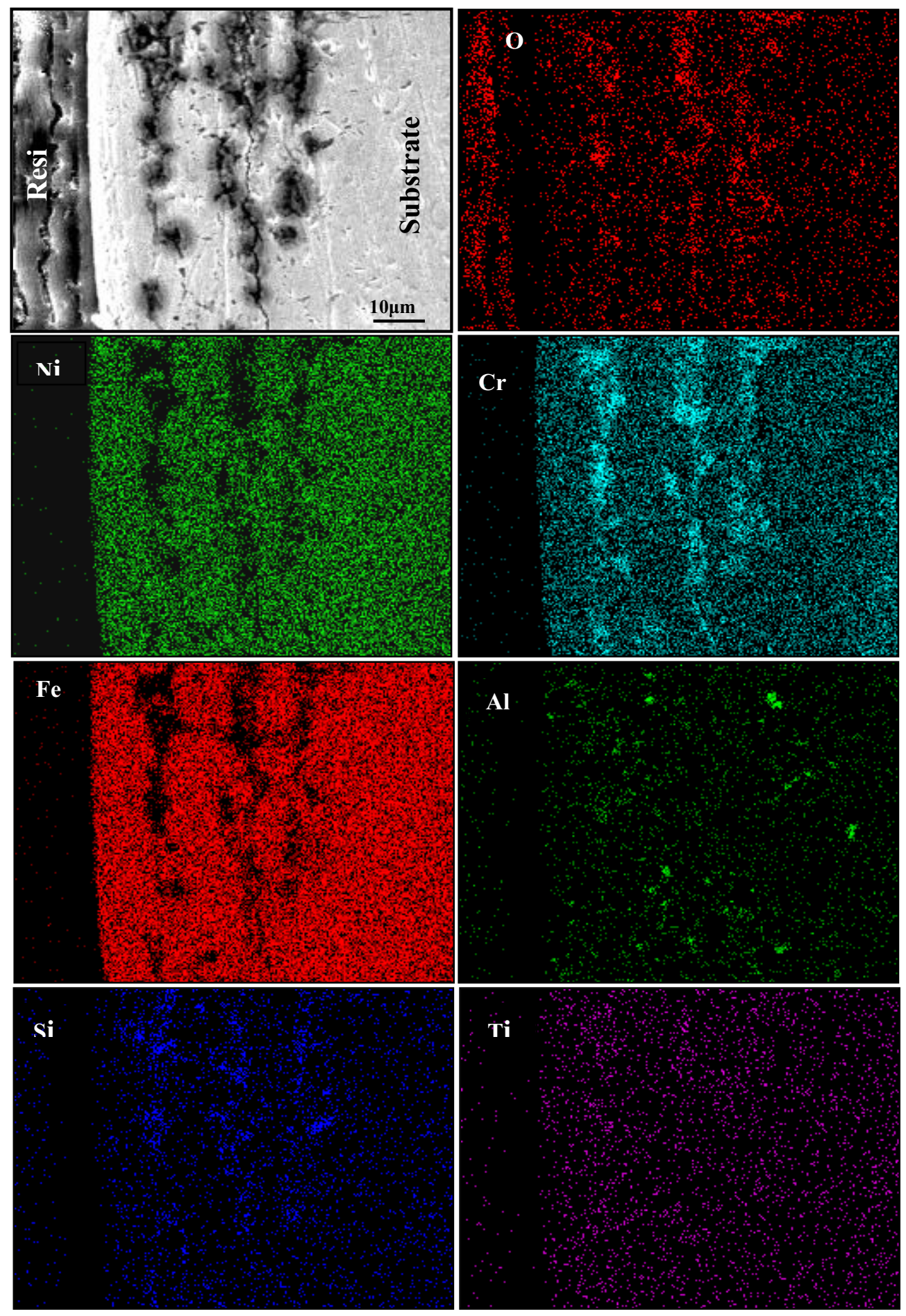

Figure 3 : Composition image (BSEI) and X-ray mappings across the cross-section of bare superfer $800 \mathrm{H}$ after $1000 \mathrm{hrs}$ of exposure to low temperature super heater zone of the coal fired boiler at $900{ }^{\circ} \mathrm{C}$. 

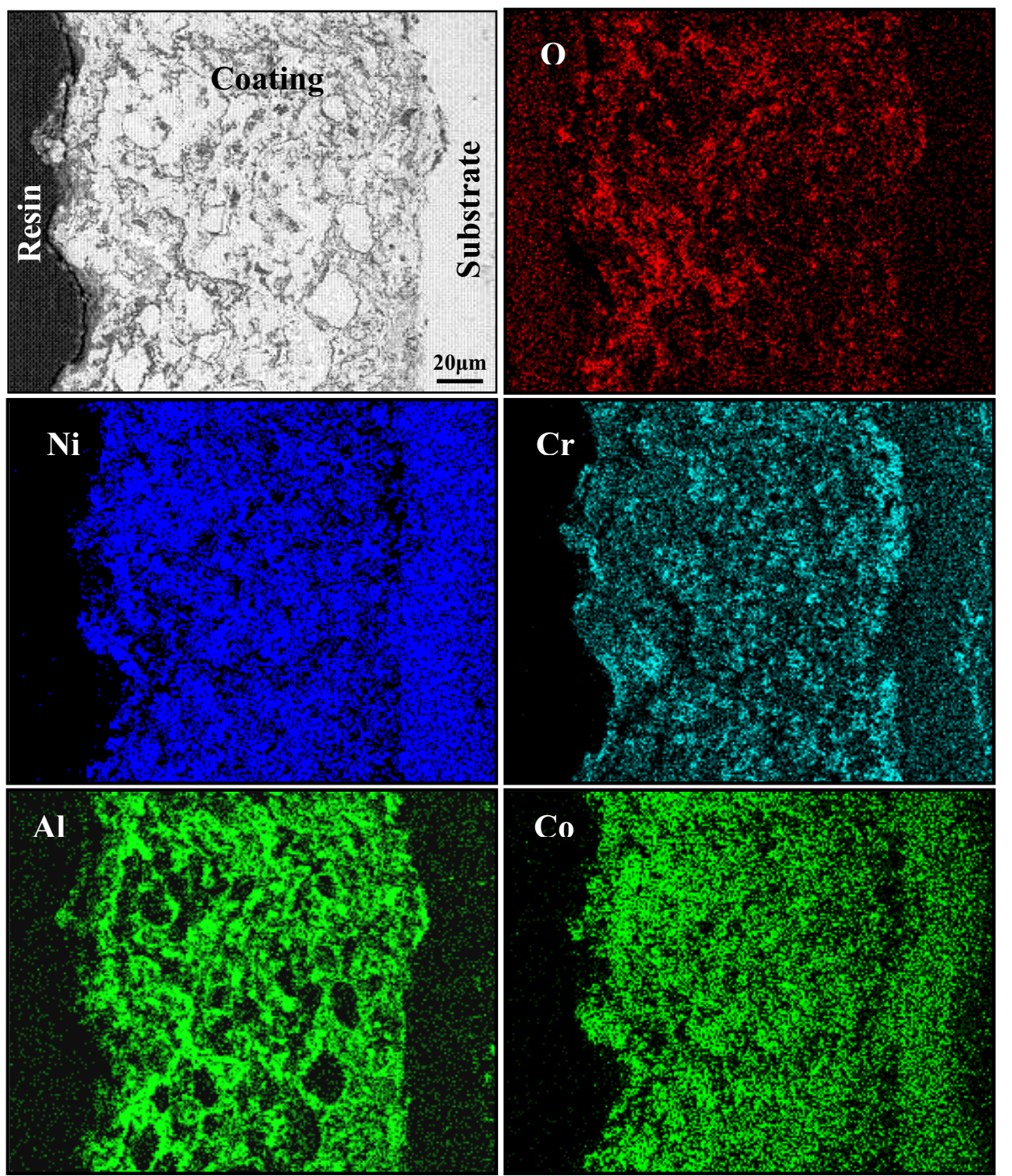

\section{Fe}

Figure 4: Composition image (BSEI) and X-ray mappings across the cross-section of D-gun sprayed. NiCoCrAlYTa coated superfer $800 \mathrm{H}$ after $1000 \mathrm{hrs}$ of exposure to low temperature super heater zone of the coal fired boiler at $900{ }^{\circ} \mathrm{C}$. 
ICPER -2014

\section{References}

1. J. R. Nicholls, N. J. Simms, W. Y. Chan, and H. E. Evans, Surf. Coat. Technol., 149 (2002) 236-44

2. N. Eliaz, G. Shemesh, and R. M. Latanision, Eng. Fail. Anal., 9 (2002) 31-43

3. K. Salmenoja, K. Makela, M. Hupa and R. Backman, J. Inst. Energy, 69 (1996) 155-162.

4. K. Natesan, Corros. 32 (1976) 364-370.

5. R. A. Rapp and K. S. Goto, The Electrochem. Soc., Pennington, N. J., (1981) 159.

6. B. S. Sidhu and S. Prakash, Oxid. Met., 63 (2005) 241-259. 